Димитрина Хамзе

Uniwersytet im. Pajsija Chilendarskiego

didiham@abv.bg

\title{
Експресивният потенциал \\ на неологизмите като катализатор \\ на гротескогенезата (върху материал \\ от романа Космос на В. Гомбрович)
}

\begin{abstract}
Hamze Dimitrina, Ekspresivnijat potencial na neologizmite kato katalizator na groteskogenezata (vyrhu material ot romana Kosmos na V. Gombrovic) (The Expressive Potential of Neologisms as the Catalyst for Grotesque Generation [Based on Excerpts from the Novel Cosmos by W. Gombrowicz]). „Poznańskie Studia Slawistyczne” 8. Poznań 2015. Publishing House of the Poznań Society for the Advancement of the Arts and Sciences, pp. 349-366. ISSN 2084-3011.

The relatively scarce surveys in the field of neologisms and the complete lack of a large scale search approach, which could unveil their diverse and multifunctional inherent capacity, posits the goal of the present survey as one of many possible vistas for the overture of their expressive potential as a powerful factor for triggering the grotesque. The results of the survey confirm the hypothesis related to the existential and expressive dynamics of neologisms - as backed by way of a plethora of linguistic means - acting as the generator of numerous functions: ludic, spontaneous, ontological and epistemological, esoteric, ritualistic and magic, bewitching, prophetic, integrative, transcending and demiurgic, communicative and entertaining.
\end{abstract}

KEYWORDS: expression; neologism; grotesque; oxymoron; communication; repetition; game, antiForm; functions; transcendence

Jest dla mnie rzeczq niewątpliwa, że zmiany środowiska cywilizacyjnego i materialnego poziomu powodują dogłębne zmiany w języku. Jeśli więc ktoś pragnie opisywać zajście poza kręgiem ziemskiej cywilizacji, to chcąc kreślić obcość czy inność tego środowiska, musi stosować neologizmy.

Stanisław Lem

Nie ma kombinacji niemożliwych... Każda kombinacja jest możliwa... Witold Gombrowicz

Неологизмите в творчеството на Витольд Гомбрович са ярки, експресивно-пластични структури с абразивно действие спрямо каноничната Форма и с подчертана гротескогенна и гротескоподдържаща 
роля. Те представляват едновременно гротескова абревиатура, компресия или стилизация, минимакет или „малка пластика” на гротесковото изображение, т.е. автономна битийност и катализатор на гротесковата осмоза в панорамното гротесково пано, в рамките на което изпълняват и ролята на семиотичен индекс. Оксиморонният принцип на построяване на новообразуваните лексеми насочва към антиномичното съжителство на разнородни и дори противоположни семи, което е категориален принцип на гротесковото конструиране. Като репрезентативни структури на гротеската и нейни а/логични алгоритми, неологизмите илюстрират в лапидарна, кондензирана форма възможността за интегративна свръхкосмизация на пространството, за универсален синкретизъм и синергетизъм на битийностите.

\section{1. Неологизмът в писателското дело на В. Гомбрович}

В произведенията на полския писател неологизмът има екстензионална природа с философско-естетически, метафизични и комуникативно-трансцендентални послания. Еластичността на категорията с респектираща вместимост на смислите и стратегиите в писателското дело на Витолд Гомбрович, ни позволява да я абстрахираме постъпателно от нейния прототип и да й придадем пространствена метаморфичност. В този ред на мисли тя се явява синоним както на отделна лексема, така и на синтактична секвенция, текстуален сегмент или дори на цяло произведение.

Бихме могли да наречем творчеството на писателя неологичен паноптикум или калейдоскоп, който генерира радиална експресивност, от която „извират” множество функции. Тази художествена неология се гради на базата на разнообразни и подчертано инвентивни неологични процедури, т.е. има процесуален и последователен характер. Ако трябва да означим със семиотичен индекс творчеството на В. Гомбрович, уместни предложения биха били навярно: неосемантема, неотекстема, макронеологема.

Неологизмите драматизират езика на писателя и същевременно свидетелстват за неговия изконен драматизъм. Ян Блонски изтъква 
спецификата на драматичния Гомбровичев език, като обръща внимание на факта, че там думите не са решения, произтичащи от ситуациите и не са затворени в тях, а точно обратното - тези думи сякаш се изговарят сами, против волята на героя, и се припознават като нееднозначни и неокончателни. Самите те управляват съдбата на персонажите или по-точно си играят с нея (Блонски 1994).

Има и една любопитна особеност на Гомбровичевото писане - неговата оригиналност се дължи не толкова на отделните лингвистични иновации, колкото на игрово-небрежното, псевдоеклектично съчетаване на познат и популярен езиков материал, с който във фигуративно-вербалните си ансамбли писателят постига неподражаем новаторски ефект.

\section{2. Неологизъм, оксиморон, гротеска}

Като разгърнато „живописно платно” на иронията, нейно пластично продължение и частична демистификация, гротеската извайва съзвучно-конфронтативни симбиози на амбивалентно-съсъществуващи битийности. Ярко изразената хибридна структура на категорията се проявява не само чрез плодотворното съчетаване на елементи от различен порядък, но и чрез тяхното дейерархизиране и равнопоставяне като ориентир за вечната „нарицателност” на всичко одушевено и неодушевено. Йерархизмът във възприемането и концептуализацията на гротеската (удивление - страх - смях) свидетелства за снемането на йерархичността в позиционирането на нещата в рамките на гротесковото изображение ${ }^{1}$. В творчеството на В. Гомбрович то е изпитателно средство за реалността на явленията в тяхната „абсурдност”.

Оксиморонният принцип на организация на гротесковото пространство кристализира експлицитно като гротескова миниатюра

${ }^{1}$ Повече за философско-естетическия, езиковия и когнитивно-прагматичния потенциал на гротеската в сатиите ни: Философско-эстетические и лингво-прагматические ресурсы гротеска (на материале творчества В. Гомбровича) (Хамзе 2013а), Гротеска и мисловно декапсулиране в романа на Витолд. Гомбрович „Транс-Атлантик” (Хамзе 2013b), Гротеската в когнитивно-прагматичен ракурс (върху материал от творчеството на Витолд Гомбрович) (Хамзе 2014). 
(или абревиатура) $)^{2}$. Некомуникативният на пръв поглед - поради шока от непривичните комбинации - оксиморон, се оказва твърде диалогичен, именно поради асоциативната си отвореност и подвижност на семантичните връзки. Експресивната тъкан на оксиморонната конструкция упльтнява и галванизира гротесковото изображение, отключвайки цяла поредица от функции. Очевидно оксиморонът не е просто стилистичен орнамент, а тип мислене за света, умален макет на всеобхватното, екслибрис на универсума.

В творчеството на В. Гомбрович той не е волна словообразователна фантазия, а последователен израз на световъзприемане и светоотношение, отворена система с непредвидими перспективи. Връзката между оксимороните и неологизмите е двупосочна, твърде често реципрочна - или неологизмите отразяват директно оксиморонния принцип на построение (,zimno-lubieżne dążenie do Katasi” $(K, 14)$, „brudna czystość” $(K, 18)$, „ciepło-chłodna ręka” $(K, 35)$, „bezwstydny wstyd” $(K, 38))$, или съдържат имплицитно ситуативен, поведенчески и светогледен оксиморон, какъвто е случаят с авторовото „изобретение” berg, или вторично оксиморонизират лексемата на повърхностно равнище, илюстрирайки на практика неограничената й словообразувателна продуктивност (bemberg, bembergować, bembergowatość, bembergowiec, benbergum, bergbembergowy, bergum-berg-bergum, berguroczystość, dyskretumberg, frajdusiumberg, hajdasiumberg, karalumbergi, lubusiumberg, lakociumbergi, pielgrzymkumberg, pocichumberg, podbembergowywanie, polizusiumberg, rozkoszumberg, tajnusiumberg, wbembergować, wymbembergować, zabergować и т.н.).

При взаимната гравитация на противостоящите компоненти на оксиморона, склонността на В. Гомбрович (която е част от неговата философско-екзистенциална позиция) да консолидира „набедени” за априорно и непоклатимо антиномични понятия, като напр. съдържание и форма, вътрешно и външно, висше и нисше, ни изглежда напълно естествена (cf. Карпински 1984: 171).

${ }^{2}$ По-подробно за оксиморона в публикациите ни: Оксиморонът - гротесковата арматура в творчеството на В. Гомбрович (Хамзе 2013c), The Grotesque Fixture Named Oxymoron (on Works by W. Gombrowicz) (Hamze 2013d). 
Оксиморонът отразява пространствената динамика в себевъзприемането, зависима от взаимодействието и взаимопроникването на две различни „аз” в различни темпорални зони, фокусиращи целия представно-сензорен и когнитивен резерв на своя носител. Оксиморонът, а респективно и неологизмът при В. Гомбрович, като че ли онагледява идеята на Войчех Карпински за адаптация и адекватно (ефикасно) функциониране в света. Интимното пространство на писателя е спойката между полюсите, която осигурява тази адаптация (Карпински 1984: 172).

\section{3. Неологизьм и игра}

Играта в когнитивния спектър на В. Гомбрович има универсални измерения. За нейната функционалност като вездесъща сила, както и за спасителната й мощ свидетелстват думите на Я. Блонски: „Swej ludycznej praktyce nadaje zatem Gombrowicz wartość uniwersalną. Sprowadza się ona do przechwytywania zaistniałych form po to, aby się od nich wyzwolić" (Блонски 1994: 106). Според Анджей Кийовски игрите са едновременно учредяващи и взривяващи затворените социални и културни системи (Кийовски 1984). Неологичната стихия в писателското дело на полския творец блестящо изпълнява точно тази роля.

В студията си „Kosmos ” $i$ antynomie Кажимеж Бартошински употребява няколко пъти понятието „игра”, акцентирайки хомофоничното му приложение у В. Гомбрович, за когото литературните занимания са аналогични на извънлитературната дейност, на специфичната житейска „игра” (Бартошински 1984: 690). В този ментален порядък неологизмите осъществяват връзката между двете „игри”, осигурявайки тяхното застьпване, наслагване и взаимно проникване. Играта с читателя, за която говори полският учен (Бартошински 1984: 677), изключва всякаква тълкувателска ултимативност и нейната заслуга до голяма степен се дължи на релативизиращата - както по отношение на смисъла, така и по отношение на интерпретацията - функция на неологизмите.

Във фундаменталното изследване на Йежи Яжембски Gra $w$ Gombrowicza неологичната игра функционира като средство за 
самоутвърждаване, като огледало, в което писателят се оглежда и което му осигурява бягство от Формата, както и съзнателното й нагаждане към личностните потребности, „прекрояването” й за целите на индивидуалното развитие (Яжембски 1982: 70). Играта на В. Гомбрович не е просто остроумно изобретение за забава и разтоварване, а винаги носи значими екзистенциални послания (Яжембски 1984: 476-477).

Игровият характер на неологизмите стимулира и укрепва техните комуникативнивъзможности. Противно на очакванията привидната акомуникативност на категорията, нейната странност и необичайност не ерозира интеракцията между продуктор и адресат, а напротив - засилва я, като същевременно подхранва както писателския талант и артистичната находчивост на своя създател, така и рецептивните способности на възприемателя. Освен това, провокира и интензифицира комуникативните и творчески функции на самата игра.

\subsection{Berg като парола за оксиморонна концептуализация}

Експресивната кондензация на неологизма berg предопределя оксиморонната му специфика. Този експресивизъм е въплъщение на оксиморонния принцип, на който се базира гротескогенезата.

1. Като когнитивно-психически и комуникативен оксиморон: пресичат се два противоположни вектора - единият е свързан с извисяване и чертае възходяща траектория към върховете на сакралното пространство чрез асоциацията с немската дума „berg” - планина, а другият сочи надолу към чувствено-фамилиарната зона на елементарните физиологични усещания чрез гъвкавите словообразувателни съчетания (lubusiumberg, podbembergowywanie, polizusiumberg, rozkoszumberg wbembergować и т.н.).

2. Като характерологичен, визуално-поведенчески и рецептивен оксиморон в ролята му на асоциация-препратка към конкретния персонаж - продуктора на berg - Леон. Със странните си, мултиплицирани до умопомрачение привички той е отблъскващ, блудкаво-погнусяващ, но с тайнствено-заклинателната мощ на своя криптоним berg е същевременно жрец, демиург. 
3. Като семантичен оксиморон - от една страна berg е свръхсемантема, т.е. единица с максимален семантичен обхват и потенциално неограничена множественост, разтегливост и динамика на смислите, а от друга - е твърде конкретизиран и „специализиран” в семантично отношение продукт, който табуира конфузен и психически дисконфортен еротичен инцидент от миналото на героя. Тук релефно се очертава едновременното действие на няколко принципа наоксиморонността: релативния, диалектичния, синхронизационния, медиативния, модално-епистемичния, гносеологичния, реверсивния и креативния. Следователно, неологичната лексема berg е колкото сврьхредуцирана (и затворена) в семантичен аспект, толкова и отворена - радиално разпръскваща множество смисли. Оттук и усещането за амбивалентност, замъгленост, неокончателност на смислите.

4. Като словообразувателен и синтактичен оксиморон - berg изглежда самодостатъчна, недеривираща конструкция, дума-енигма, дума-шифьр, но същевременно е и с безкрайна словообразувателна и синтактична продуктивност. Изобилието от лексикални деривати и фразеологични съчетания разкрива семантичния „простор” на лексемата и разчупва представата за нейната херметична, моноцентрична ориентация.

5. Като стилистичен оксиморон - разглежданата лексема може да бъде квалифицирана като представителна както за популярно-тривиалния, така и за високия, йератично-церемониален стил.

6. Като комуникативен оксиморон - berg е едновременно мълчание и словоохотливост; акомуникативност, комуникативна репресия или рестриктивна избирателност на комуникативния партньор в антропологичен план и интензивна перманентна комуникация, свръхи свръхкомуникативност в космически план.

„Бемберговата” теория, както отбелязва В. Карпински, отразява способността на човешкото съзнание да придава смисъл на света (Карпински 1984: 178). 


\section{1. Експресията на неологизмите като комуникативен стимул}

Илюзорният комуникативен дефицит на гротеската като „законспирирано" естетическо платно-послание за шепа посветени, е многократно и многостепенно опровергаван от комуникативната полифония на изображението. Гротеската не е трудно рецептивна. Именно благодарение на ярката си, пластична образност тя сякаш всмуква зрителя, прави го творчески съучастник и съавтор в гротесковата „постановка”. Така дистанцията между продуктор и адресат се свежда до минимум.

„Недъгавостта” на общуването, за която говори Емил Чоран (2006), тук по парадоксален начин се компенсира от най-непроницаемия словесен алгоритъм berg, който звучи като езотерична аксиома в устата на Леон и като потенциално универсален семантичен компресив. Дегизирана като отрицание на комуникацията, тази криптограма носи подчертан комуникационен потенциал на няколко нива. Чрез нея: 1. изолацията от обкръжението се компенсира от пльтно сближаване с избрания комуникативен партньор - Витолд (наратора); 2. призоваването на близките и гостите като публика на скритата от очите им церемония на автоеротичното тайнство на героя означава покана за общуване в друго измерение; 3. осъществяването на директно общуване от страна на Леон с вибрациите на космичното представлява „телепортиране” в друга зона - на свръхкомуникативната конвергенция на нещата в монументалната симфония на Абсолюта.

За многозначното мълчание на berg говори самият писател: „Ale milczenie to całkowicie harmonizuje z takim interesującym domysłem. Jeśli bowiem dzięki bergowaniu udaje się twórcy znaleźć ,,po tamtej stronie, po stronie szarady” ( $D z$ III, 175) и ни пренася в „,fferę, gdzie działy się tajemnice, w sferę hieroglifu" $(K, 68)$, а думите му допълва коментарът на Александра Окопен-Славинска: „to oczywiste, że nie zechce on wystąpić w roli gadatliwego przewodnika po tych sferach" (Окопен-Славинска 1984: 705).

Интензивната комуникативност на неологизма се потвърждава от универсалната му съчетаемост в словообразувателно отношение. Така както berg притежава свръхдеривативен потенциал и поражда неограничен брой производни конструкции (функциониращи като 
различни категории думи: съществителни, прилагателни, глаголи, наречия), така и гротеската сплотява и хармонизира нещата в себе си, осигурявайки им комуникативно съзвучие. Експресивната „температура" на новия синтактичен порядък отново привлича вниманието на полската изследователка, чиито разсъждения (Окопен-Славинска 1984: 697) подкрепят тезата ни, че бергоподобните вербални творения стават миниатюра на космическата симфония.

\section{2. Експресията на неологизмите като анти-Форма или естетическата Форма срещу Формата}

Отричането на Формата чрез Контраформа е лайтмотив в творчеството на В. Гомбрович. Достоен палиатив за Формалната ни закрепостеност е гротеската, която противодейства с пластиката на естетическата си Форма. По същество тя е Антиформие, контраудар срещу Униформието, Формошествието и Формолектиката (по модела на еклектиката). Тази гротескова Форма е вечно ставаща, незавършена, креативна ирония на Формалността. Гротесковата офанзива срещу Формата изльчва специфична красота, която не е непременно турпистична естетика, а уникална трансформация и сублимация на естетическия канон. Релативизирането и разграждането на Формата, Раз-формироването (или Раз-формянето) чрез кинетичната гротеска на експресивните (литанични) словесни потоци, отрежда почетно място на красотата, не просто като дедуктивна производна, заради подразбиращата се естетическа природа на всяко изкуство, а като директно присъстие в гротесковото изображение. Именно защото руши стереотипите, уни-формите и техните синонимни субститути (напр. $K, 103$ ).

\section{3. Експресията на неологизмите като развенчаване на „абсурдната" представа за абсурда}

Тайнствеността е иманентна черта на условно приемания от нас абсурд, а чрез него и на гротеската - подсказва ни двойно възприемане и ни държи в полето на трайното съмнение: дали нещо се осмива, 
защото е аномално или пък се утвърждава, защото се оказва естествено, т.е. критикува се менталния рефлекс да го възприемаме като анормално; иронизира се картинно инерцията и униформата на мисълта. Съзвучие на антиномиите в рамките на гротеската, вродената им симбиотичност, онагледява безсмъртието на идеите и на идеята, че всичко е възможно, в това число и собственото ни безсмъртие. Чрез гротеската се откроява не толкова лиминалната и конклузивната, колкото иновативната роля на смъртта (сериите от некротични прогресии в Космос) като задължителен компонент от космическата ритмика.

Неологичната реч на Леон е индиректен призив за нов тип комуникиране. Експлозията от оказионализми - миниатюри на вселенската хармония, за които можем да търсим екзистенциално тълкуване - е ирония на човешката неспособност да се справи с психическата си дезинтеграция, дезориентация и декомпозиция, което отрежда на индивида ролята на жертва пред олтара на непреодолимата триада светове - свойския делничен свят, енигматичния, напроницаем космос и девиантния свят на психо-емоционалния отскок като опит за помирение (съгласуване) на първите два ${ }^{3}$. Оксиморонният взрив в индивидуализмите на Леон може да бъде тълкуван като успешна езикова рационализация целящапрескачане на зеещата пропаст между двата противостоящи свята: „Niech pan sobie wyobrazim - człowiek siedzim na pniusium - nie mówiusium - za godzinę marszusium - proszę się nie denerwusium - tutaj spoczusium i odetchnusium”, „do dziś przechowusium”, „niczego nie zauważymus”, ,przepadupcium, zapadupcium”, „świntusium zaświntowanko" (К, с. 131, подчерт. са мои - Д.Х).

\section{4. Експресията на неологизмите като проявление на плодотворно отрицание}

Отрицанието маркира когнитивните ни усилия - първичния ни допир с външния свят, както и конклузивните ни рефлексии относно

${ }^{3}$ Интересно тълкуване на триадата от светове в творчеството на В. Гомбрович прави Михал-Павел Марковски в монографията си Czarny nurt. Gombrowicz, świat, literatura (Марковски 2004). 
непознаваемостта на света и невъзможността да го познаем, а още по-малко о-познаем.

Анамнезата, припомнянето на архетипа е евокативната природа на гротесковото изображение чрез експресията на неологичното. А съществуването на тайната е възможно само благодарение наотрицанието . „Тайната е онова, което по самото си същество никога не може да бъде разкрито" (Чоран 2006: 58). Енигмата е ирония на самодоволното ни самозальгване с ,,разбулването им”. Заклинателното слово: „Bembergowanie bembergiem w berg” е всъщност паролата на хармоничния комуникативен дует Леон - Витолд и „вълшебната фраза" за о-съзвучаване с пулса на Вселената.

Експресивността на неологизмите издава отрицанието на рутинната ни представа за абсурдността, която в действителност повдига градуса на същинската комуникация.

\section{5. Експресията на неологизмите като „трамплин” за повторението}

На Хосе Ортега-и-Гасет прави впечатление, че „още старият Аристотел отбелязва, че различните неща се различават по това, по което си приличат, тоест по общото в тях. Само защото всички предмети имат цвят, забелязваме, че те се различават по цвят помежду си" (Opтега-и-Гасет 1984: 237). Повторението е централен принцип на света и съществуването - те се крепят на него. Без него не би имало приемственост и унаследяване на биологични и ментални модели, не би съществувало и понятието архетип като източник и свидетелство за една безкрайна поредица от повторителни действия на човечеството, без която не би било възможно каквото и да е общуване, какъвто и да е превод, какъвто и да е културен обмен.

Неологичните „вакханалии” на Леон с тяхната сеизмична сила принципно се повтарят като рефрени, сякаш за да ни предпазят от автодеструкция. Наблюдението на А. Окопен-Славинска - по пътя на асоциацията и аналогията - сякаш насърчава към утвърждаване на повторението и като личностна уникалност, опит за самоидентификация, за самодостатъчност и арбитралност на собственото битие 
(Окопен-Славинска 1984: 697). Тавталогията (позиционен вариант или частен случай на повторението) може да се приеме за особен вид лексикално-синтактично степенуване, а в когнитивен план - за контактологично сравнение, - съвсем не е редундантна езикова небрежност или разсеяност, нито излишно лингвистично престараване, а художествено (експресивно) средство за засилване на ефектаи за подчертаване на категоричността на оценката или решението с гротескова настойчивост. При В. Гомбрович тавтологичният принцип (често в комбинация с дословно повторение) намира широко приложение в процеса на неологизация: „nieruchomo nieruchomiał”, ,,a tu wisielec wisiał, trup brutalny!”, „z girlandą natury (...) z wyniosłością wzniosłą i jedyną”, „Oto ptak olbrzymi zawisa nade mną wiszący”, „A jednak ten FAKT wisiał, wiszący fakt, fakt ludwikowaty wiszący" $(K, 138,140)$. Деривацията също е възможна, благодарение на повторението.

\section{6. Функционалният диапазон на неологизмите - следствие от експресивната им консистенция}

Тук трябва да направим уточнението, че благодарение на експресивния „интензитет” на неологизмите като градиво на гротесковата композиция, актуализираните в собствената им зона функции стават автоматично гротескови функции.

1. Космотворческа функция.

Ритмичната, почти рефренична повторителност на абсолютния, извънсистемен неологизъм berg - и директна, и като изходна база, опорна матрица за всевъзможни деривати (което мултиплицира самата повторителност) - пре-създава и въз-създава универсума с езикови средства. Еруптивната и съзидателна мощ на експресионизма сякаш реконструира, реанимира и реинтерпретира космическото пространство. Образец на хармоничен дует като проекция на абсолютната съгласуваност и син-фоничност е диалогът между Леон и Витолд, основан на латентно разбирателство и мълчаливо съгласие $(K, 144)$.

Повсеместното семантично разстилане на berg и неговата универсална съчетаемост онагледяват неговата космогонична и космоподражателна функция. Неологизмът е субститут на самия денотат 
и предава реалната осезаемост на предметите, както и техните интегративни връзки помежду им (Окопен-Славинска 1984: 700). Сензорно-соматичната фактура на неологизмите откроява ролята на сетивния опит в познанието за света, на което обръща специално внимание Михал-Павел Марковски. Светьт е естествена производна на индивидуалната чувствителност (Марковски 2004: 379).

Ономатопеичните меандри, ехолалиите и динамичното „битие” на berg освен за материална сетивност на окръжаващия свят, създават и впечатлението за физическо присъствие и субстанционалност на неологизма едновременно като съставна част от Космоса, негов реален субститут ипредставител. Неологичната експресия в повествованието сигнализира космическата множественост на нещата и техните варианти, проверена сякаш от реалния допир с тях.

Символизирайки консолидацията на нещата, berg сублимира множествеността, превръща се в знак на автоконтекстуалност и самодостатъчност, в аналог на новата събитийност. Неяснотата и „посветителската" яснота в семантичния профил на berg наподобяват съобщение Хаос - Космос. Непроницаемото, непрогледното е потенциално творческото и включва в себе си самото циклично повтаряне на хаос и ред.

Усещането за скука идва, когато картината се размазва и помътнява, подсказвайки, че Всичко-то и Нищо-то са равни. Порядъкът предвещава Хаоса и обратно; отношенията са реципрочни и периодично се налага реорганизация на космическото пространство. Йежи Пашек и Филип Мазуркевич също долавят космизиращите енергии на неологизмите (Пашек, Мазуркевич 1998: 31).

Wbembergowanie представлява синтез на оплодителната мощ, поддържаща космическото равновесие, а в симетричната равнина „акомпанират” паралелизми, обединени около централни лексеми като: wbijanie, wsuwanie, przeżuwanie, tykanie. Всъщност повечето от героите: Kulka, Ksiądz, Ludwik, Katasia,... имат своята лична тайна, своя berg чрез който общуват с космичното.

Най-сетне berg отразява двойствения облик на Космоса и раздвоеното му възприемане - очарованието и удоволствието от съвършената хармония и шока от неизвестното, от заплахата на непредсказуемото.

2. Комуникативна функция.

Причудливата конфигурация на неологизмите създава измамното 
впечатление за ограничена или потисната комуникативност, но всъщност, както се опитахме да покажем по-напред в изложението, те повишават комуникативния градус на друго равнище. $\mathrm{C}$ мощния си експресивно-естетически заряд, като част от гротесковата структура, укрепват диалога Автор - Читател и възцаряват космическата свръхкомуникативност между хора, предмети, явления и събития.

3. Креативна функция.

Неологизмите са продукт и емблема на творчество par excellence, а гротеската е най-творческата категория. Експресивният им потенциал е гаранция за нови творчески инвенции и за постоянно обновяване на гротесковото изображение.

4. Семиотична функция.

Експресивната наситеност на неологизмите ги прави знакови „фигури" в гротесковото пространство. Те са едновременно знак на собствените си денотати и микросемиотеми на гротесковата панорама.

5. Естетическа (пластично-изобразителна) функция.

Вече стана дума за гротеската като най-ярка естетическа категория. Експресивната функция е пряко свързана с естетическата, а неологизмите като живописно въплъщение на оксиморонния принцип съчетават вербалното с „картинното” (визуално) изображение.

6. Синестезивна функция.

В рамките на гротеската неологизмите комбинират звук, образ и усещане.

7. Игрова и развлекателна функция.

Играта е първична човешка функция, един от фундаменталните духовни елементи на живота и безкористен път към истината. Тя е същностна за изкуството и особено за категориите на комичното. Големите теоретици на играта: Кант, Шилер, Ницше, Шопенхауер, Шпенглер, Ортега-и-Гасет, изтъкват връзката между игра, въображение и удоволствие. Развлечението - едно от големите измерения на културата - е „изкореняване” от реалния живот в името на един имагинерен, фантасмагоричен живот. Неологизмите са модел на игра както езикова, така и поведенческа, „сюжетна”, която прераства в голяма гротескова игра.

8. Провокативна, анти-Формална функция.

Експресивният ресурс на неологизмите е „взривно вещество” 
за формалната стагнация. Те са субстанционални експлозиви в гротесковата зона и правят от гротеската най-антиформалната от естетическите категории. Тя противодейства на стереотипната Форма с артистичната си контра-Форма.

9. Сакрална, езотерична и профетична функции.

Неологизмите като магически формули и в ролята си на жреческо слово сакрализират семантичните послания и изпълняват антиципативно-пророчески функции.

10. Евристично-демиургична функция.

Чрез експресивната сила на неологизмите в гротескогенезата техният автор влиза в ролята на демиург - създава нови галактики, нови мрежи от отношения, нови комуникативни платформи, нови онтологични конфигурации на битийностите.

11. Трансцедентираща функция.

Тази функция е пряко свързана с предходната. Новата постановка на предметите и техните взаимовръзки се дължи на трансцедентирането им, благодарение на неологизмите, а припокриването на орбитите на автора и възприемателя е възможно на трансцендентно равнище.

12. Епистемологична функция.

Експресивният профил на неологизмите стимулира и проявлението на когнитивно-познавателния им потенциал. По този начин в гротесковата зона се разширяват познавателните възможности както на автора, така и на адресата, обогатяват се познанията им за света и неговите метаморфози.

13. Интегративна, хармонизираща функция.

Конструкцията на неологизмите е нагледно доказателство (и еталон) за интегритет между съставките на лексемата, а гротеската като уедрено паное релефна илюстрация на интерактивния и хармонизиращ принцип, чието безотказно действие се проявява в успоредяването, де-йерархизацията и оравноценностяването на предметите.

14. Корективна функция.

Неологизмите не натрапват рецепти за съвършенство, но прокарвайки алюзията, че нещата никога не са еднозначни, подобряват самата природа на перцепцията, на общуването и интерпретацията. Гротеската предлага нестандартна визия за устройството и функционирането 
на космоса и така коригира баналните и неадекватни представи за него. А. Окопен-Славинска също употребява оксиморон, споделяйки наблюденията си: „Berg jest więc szansą dla niedoskonałości (...) sposobem wzniesienia niższości nad wyższość i słabością opanowania siły" (Окопен-Славинска 1984: 704).

Направеният преглед на избраната проблематика ни навежда на следните изводи:

1. Експресивният потенциал на неологизмите се асоциира с неосемантизма на гротеската и поражда нейната уникалност, устремена към „макетно” възстановяване на универсалния баланс чрез интелектуално-естетическа синтеза.

2. Слабата възможност за дешифриране на неологизмите в разглеждания роман на В. Гомбрович засилва тяхната естетическа, експресивна, космотворческа и гротескоподдържаща роля.

3. Оказва се, че не е толкова важно какво означават неологизмите, а какво могат да „изиграят”. Техните интерпретативни потенции „застават” в подкрепа на трансцендентално-игровата функция на гротеската.

4. Неологизмите разширяват границите на интерпретативната свобода.

5. Неологизмите имат оксиморонна природа, която „предават” на гротеската.

6. Неологизмът тръгва от отделна дума, но експресивната му динамика разширява неимоверно пространствените му параметри, т.е. води до неговото екстензионално нарастване, което може да го превърне в синоним на цяло произведение - продукт на неологията като процес.

\section{Литература}

Ортега и Гасет Х., 1984, Естетически есета, София.

Хамзе Д., 2010а, Ироногенната функиия на негаиията, в: Научни трудове на ПУ „П. Хилендарски”, т. 48, кн. 1, СБ. А, с. 284-296.

Хамзе Д., 2010b, Итеративната модалност като културогема в творчеството на Витолд Гомбрович, в: Научни трудове на ПУ „П. Хилендарски”, т. 48, кн. 1, СБ. А, с. 373-384. 
Хамзе Д., 2011, Архетипната анатомия на езика като демистификатор на езиковия канон (по „Космос” на Витолд Гомбрович), в: Истина, мистификация, лъжа в славянските езици, литератури и култури, София, с. 145-154.

Хамзе Д., 2012а, Евристика на словото. Трансгресивните иновации на писателя (върху текстове на Витолд Гомбрович), в: Годишник Наука - Образование изкуство, т. 6, ч. 2, Благоевград, с. 173-180.

Хамзе Д., 2012b, Езиковата еквилибристика на Гомбрович - ефективна стратегия в борбата срешу нашествието на Формата, в: Славистиката в глобалния свят - предизвикателства и перспективи, Благоевград, с. 205214.

Хамзе Д., 2012c, Мястото на емоциите в категориите на комичното, в: Сборник с научни трудове от национална конференция с международно участие „, 40 години Шуменски университет 1971-2011 2”. Факултет по хуманитарни науки, Шумен, с. 526-534.

Хамзе Д., 2013а, Философско-эстетические и лингво-прагматические ресурсы гротеска (на материале творчества В. Гомбровича), в: Verbal culture of the humanity through the prism of ages (London, July 18-July 23, 2013), London, c. 51-56.

Хамзе Д., 2013b, Гротеска и мисловно декапсулиране в романа на Витолд Гомбрович ТРАНСАТЛАНТИК, в: Комичният роман. Анализи и прочити, София, с. $152-175$.

Хамзе Д., 2013с, Оксиморонът - гротесковата арматура в творчеството на В. Гомбрович, в: Актуални проблеми на българистиката и славистиката. Втора международна конференция, 9-10 ноември 2012 г., Велико Търново, c. 414-423.

Хамзе Д., 2014, Гротеската в когнитивно-прагматичен ракурс (върху материал от творчеството на Витолд Гомбрович), Съпоставително езикознание кн. 4, София, с. 41-54.

Чоран Е., 2006, Наръчник по разложение, София.

Bartoszyński K., 1984, „Kosmos” i antynomie, w: Gombrowicz i krytycy, red. Z. Łapiński, Kraków, s. 654-691.

Błoński J., 1994, Forma, śmiech i rzeczy ostateczne. Studia o Gombrowiczu, Kraków.

Budzyk K., 1973, Sprawa neologizmów w literaturze, w: Stylistyka polska. Wybór tekstów, red. E. Miodońska-Brookes, A. Kulawik, M. Tatara, Warszawa, s. 169-178.

Gombrowicz W., 1986, Dziennik 1961-1966, Dzieła, t. 11, Kraków.

Gombrowicz W., 2000, Kosmos, Kraków.

Hamze D., 2013d, The Grotesque Fixture Named Oxymoron (on Works by W. Gombrowicz), w: Applied and Fundamental Studies. Proceedings of the 7th International Academic Conference. November 29-30, 2014, St. Louis, USA, St. Louis, Missouri, s. 383-390.

Jarzębski J., 1982, Gra w Gombrowicza, Warszawa.

Jarzębski J., 1984, Kategoria ,,gry” w poglądach Gombrowicza, w: Gombrowicz i krytycy, red. Z. Łapiński, Kraków, s. 467-489. 
Karpiński W., 1984, Gombrowiczowska przestrzeń, w: Gombrowicz i krytycy, red. Z. Łapiński, Kraków, s. 171-183.

Kijowski A., 1984, Strategie Gombrowicza, w: Gombrowicz i krytycy, red. Z. Łapiński, Kraków, s. 429-465.

Markowski M.P., 2004, Czarny nurt. Gombrowicz, świat, literatura, Kraków.

Okopień-Sławińska A., 1984, Wielkie bergowanie, czyli hipoteza jedności „,Kosmosu”, w: Gombrowicz i krytycy, red. Z. Łapiński, Kraków, s. 693-706.

Paszek J., Mazurkiewicz F., 1998, PrzeczyTacie „Ferdydurke”, Katowice. 